\title{
ET-1 regulates the human umbilical vein endothelial cell cycle by adjusting the ERß/FOXN1 signaling pathway
}

\author{
Yuyan Wang, Yunjun Ruan, Saizhu Wu \\ Department of Gerontology, Nanfang Hospital, Southern Medical University, Guangzhou, China \\ Contributions: (I) Conception and design: Y Wang, S Wu; (II) Administrative support: S Wu; (III) Provision of study materials or patients: Y Ruan; (IV) \\ Collection and assembly of data: Y Wang, Y Ruan; (V) Data analysis and interpretation: All authors; (VI) Manuscript writing: All authors; (VII) Final \\ approval of manuscript: All authors. \\ Correspondence to: Saizhu Wu; Yunjun Ruan. Department of Geriatrics, Nanfang Hospital, Southern Medical University, Guangzhou, China. \\ Email: flamewusaizhu@163.com; ryj86@126.com.
}

Background: Atherosclerosis (AS) is a chronic and progressive disease primarily induced by inflammation of the arterial blood vessel wall. Investigating the function and molecular regulation mechanisms of ET-1, $\mathrm{ER} \beta$, and FOXN1 in disease models will provide new targets and means for clinical treatment.

Methods: The effects of ET-1 on oxidative stress in HUVEC were verified through quantitative polymerase chain reaction (qPCR), western blot, flow cytometry, as well as dual luciferase reporter gene and biochemical assays.

Results: Compared with the ET-1+ negative control (NC) group, the ER $\beta$ messenger ribonucleic acid (mRNA) expression level was significantly reduced, and the FOXN1 mRNA expression level increased markedly in the ET-1 + ER $\beta$ small interfering ribonucleic acid (siRNA) group. Meanwhile, the FOXN1 mRNA expression level was significantly reduced in the ET-1 + FOXN1 siRNA group. FOXN1 promoter luciferase reporter gene activity was notably enhanced in the ER $\beta$ siRNA group compared with the siRNA control group. Compared with the ET-1 + NC group, the levels of reaction oxygen species (ROS) in the ET-1 + ER $\beta$ siRNA group increased considerably, the superoxide dismutase (SOD) level was significantly reduced, and the G0/G1 phase cell ratio was reduced. In addition, the protein expression of ER $\beta$ and cyclin B1 (CCNB1) was markedly reduced, whereas the protein expression of cyclin A2 (CCNA2), cyclin D1 (CCND1), and cyclin E1 (CCNE1) increased substantially. The opposite result was observed in the ET-1 + FOXN1 siRNA group.

Conclusions: ET- 1 can contribute to the expression of ER $\beta$ and FOXN1. ER $\beta$ can inhibit the expression of FOXN1 by regulating promoter activity. The ET-1/ER $\beta / F O X N 1$ signaling pathway is involved in the regulation of oxidative stress and cycle progression in HUVEC. This study provides a new mechanism for the regulation of umbilical vein endothelial cells. The ET-1/ER $\beta / F O X N 1$ signaling pathway may provide novel therapeutic targets and strategies for the treatment of atherosclerosis.

Keywords: HUVEC; ET-1; ER $\beta$; FOXN1; cell cycle

Submitted Sep 01, 2020. Accepted for publication Nov 03, 2020.

doi: $10.21037 / \mathrm{atm}-20-6560$

View this article at: http://dx.doi.org/10.21037/atm-20-6560 


\section{Introduction}

Atherosclerosis (AS) is a chronic and progressive disease primarily induced by inflammation of the arterial blood vessel wall. Its pathogenesis involves complex interactions between inflammatory cells, vascular endothelial cells (VECs), and vascular smooth muscle cells (VSMCs). Under the stimulation of pro-inflammatory factors, inflammatory cells produce a large number of inflammatory factors, and the function of VECs changes and promotes the migration and proliferation of VSMCs to the intima, ultimately leading to the occurrence and development of AS (1-4). During the development of atherosclerosis, the intima of the artery is the earliest site of accumulation, mainly characterized by pathological changes including damage to the vascular endothelium, thickening of the muscle layer caused by thrombus formation and fibrosis after smooth muscle cell apoptosis, shedding of atheromatous plaques after vascular remodeling, and apoptosis $(5,6)$. Therefore, the dysfunction of VECs is an important cause of atherosclerosis $(7,8)$. However, the molecular mechanism of the abnormal regulation of endothelial cells is still unclear, and there is a pressing need for this problem to be urgently resolved. Human umbilical veins are easy to operate because they have large lumens and no branches, and the endothelial cells obtained are relatively pure (9). They also exhibit similar biological characteristics to arteries in many respects, and are particularly suitable for studying atherosclerosis and other diseases $(10,11)$. Gong et al. found that vaccarin could inhibit the occurrence of AS by preventing the HUVEC EndMT, inflammation and apoptosis induced by ox-LDL (12). However, the specific molecules involved in regulating HUVEC during the occurrence and development of AS are not clear.

Research into the effects of endothelial cells has determined that endothelin (ET) is composed of 21 amino acids in the cultured porcine aortic endothelial cells, and confirmed that it is an effective vasoconstrictor peptide (13). Five members of the endothelin family have been discovered: ET-1, ET-2, ET-3, ET-4, and ET1-31, of which ET-1 is the main subtype in humans (14). Previous studies have reported that ET-1 can regulate vasoconstriction through autocrine or paracrine methods and promote mitosis and smooth muscle proliferation, resulting in a thickening and remodeling of blood vessel walls (15). Estrogen is a steroid hormone that plays a key role in the growth, development, and maintenance of various mammalian tissues (16). The biological effects of estrogen are primarily mediated by intracellular estrogen receptors, $\mathrm{ER} \alpha$ and $\mathrm{ER} \beta$ (17). As a classic nuclear receptor, ER $\beta$ is a key regulator of growth and differentiation in various tissues, and has a wide and important physiological role (18). Furthermore, previous reports have shown that $\mathrm{ER} \beta$ is also involved in the occurrence and development of various diseases including cancer and cardiovascular diseases (19).

Forkhead box protein N1 (FOXN1) is a member of the fork-shaped head box gene family located on chromosome 17 and is involved in various cellular processes such as development, metabolism, and aging. It is predominantly expressed with thymic epithelial cells and is an important transcriptional regulator $(20,21)$. FOXN1 plays an important regulatory role in tumors, immunodeficiency, and epithelial cell growth $(22,23)$. Investigating the function and molecular regulation mechanisms of ET-1, ER $\beta$, and FOXN1 in disease models will provide new targets and means for clinical treatment. However, the role of these important regulatory factors in the abnormal regulation of human umbilical vein endothelial cells (HUVEC), and especially the relationship between the three and the molecular regulatory mechanisms, remains unclear.

Therefore, this study is the first to explore the regulatory effects of ET-1 on ERh and FOXN1, and the role of ET-1, $\mathrm{ER}$, and FOXN1 in oxidative stress and cell cycle regulation of HUVEC. This will provide a new therapeutic target for the clinical treatment of AS. We present the following article in accordance with the MDAR reporting checklist (available at http://dx.doi.org/10.21037/atm-20-6560).

\section{Methods}

\section{General information}

HUVEC were provided by Guangzhou Yeshan Biotechnology Co., Ltd. FOXN1 and ER $\beta$ small interfering ribonucleic acid (siRNA) were provided by Shanghai GenePharma Co., Ltd. ET-1 was purchased from CALBIOCHEM.

\section{Instruments and reagents}

Fetal bovine serum for cell culture (Cat. No. SH30087.01), high glucose Dulbecco's Modified Eagle Medium (DMEM) (Cat. No. SH30022.01B), penicillin (Cat. No. SH30010), and potassium phosphate buffered saline (PBS) (Cat. No. SH30256.01B) were purchased from Hyclone (USA).

Consumables for cell experiment: 6-well cell culture 
plates (Cat. No. 040810004), 24-well cell culture plates (Cat. No. 3548), 48-well cells culture plates (Cat. No. 051010001 A) were purchased from CORNING (USA). 12-well cell culture plates (Cat. No. 3524) and 96-well cell culture plates (Cat. No. PPP-001-030) were purchased from NEST (Hong Kong, China). Pasteur pipette $(3 \mathrm{~mL})$ was purchased from JET BIOFIL (Guangzhou, China).

Instruments included the following: Suzhou Antai clean bench (SW-CJ-IFD), low speed centrifuge (Zhongjia, SC3614), inverted optical microscope (OLYMPUS CKX41, U-CTR30-2), cell culture incubator (Thermo scientific, HERACELL150i), and inverted fluorescence microscope (Leica, DMI6000B).

\section{Cell culture and grouping}

HUVEC cells were adherently cultured in DMEM containing $10 \%$ fetal bovine serum in a $37{ }^{\circ} \mathrm{C}, 5 \%$ carbon dioxide $\left(\mathrm{CO}_{2}\right)$ cell incubator. The medium was changed every 2-3 days to maintain a good cell growth state. After the cells grew to between $70 \%$ and $80 \%$ of the bottom of the culture flask, they were digested, collected, centrifuged, and passaged with $0.25 \%$ trypsin-ethylenediaminetetraacetic acid (EDTA) solution. The cells in a logarithmic growth phase were used for the experiment. After the cells grew to sub-confluence, the corresponding experimental treatments were carried out. According to experimental needs, cells were divided into eight groups: (I) blank control group (cell); (II) siRNA control group (NC); (III) ER $\beta$ siRNA; (IV) FOXN1 siRNA; (V) 100 nM ET-1-48 h; (VI) ET-1 + NC; (VII) $\mathrm{ET}-1$ + ER $\beta$ siRNA; (VIII) ET-1 + FOXN1 siRNA.

\section{$R N A$ extraction and reverse transcription}

Total ribonucleic acid (RNA) was extracted using the TRIzol method. After collecting the cells of different groups, $1 \mathrm{~mL}$ of TRIzol (Invitrogen) solution was added to the cells, mixed well by pipetting to ensure that the cells fully lysed, and let stand for $5 \mathrm{~min}$. Next, $200 \mu \mathrm{L}$ of chloroform was added, shook vigorously, and mixed for $30 \mathrm{~s}$ to ensure that the water and organic phases fully contact, and then let stand $2 \mathrm{~min}$. The cells were subsequently centrifuged at $14,000 \times \mathrm{g}$ for $15 \mathrm{~min}$ at $4^{\circ} \mathrm{C}$. At this stage, it can be seen that it is divided into three layers, and the RNA was in the upper aqueous phase. The RNA was carefully pipetted into another new ribonuclease (RNase)-free Eppendorf (EP) tube. An equal volume of isopropanol was added, mixed gently and fully, and let stand for $10 \mathrm{~min}$ at room temperature to precipitate RNA. It was subsequently centrifuged at $14,000 \times \mathrm{g}$ for $10 \mathrm{~min}$ at $4^{\circ} \mathrm{C}$. The RNA precipitate was collected and the supernatant was removed. It was subsequently washed twice with $75 \%$ ethanol, added with $20 \mu \mathrm{L}$ of diethyl pyrocarbonate (DEPC)-treated water to dissolve the precipitate after airdrying on super-clean table.

Next, the genome removal operation was performed as follows: RNase-free deoxyribonuclease (DNase) I (Promega) was used; the reaction solution was configured, digested at $37{ }^{\circ} \mathrm{C}$ for $30 \mathrm{~min}$, and then inactivated at $65^{\circ} \mathrm{C}$ for $10 \mathrm{~min}$. An equal volume of phenol was subsequently added, mixed upside down and well at 10,000 rpm, centrifuged for $5 \mathrm{~min}$, and then the supernatant was taken. Next, an equal volume of chloroform was added, mixed upside down and well at 10,000 rpm, centrifuged for $10 \mathrm{~min}$, and then the supernatant was taken. After this, an equal volume of isopropanol was added, mixed gently and fully, and let stand at $-20{ }^{\circ} \mathrm{C}$ for $15 \mathrm{~min}$. It was then centrifuged at $10,000 \times \mathrm{g}$ for $10 \mathrm{~min}$ at $4^{\circ} \mathrm{C}$; the RNA pellet was collected and the supernatant was removed. Finally, it was washed twice with $75 \%$ ethanol, dried on a super-clean table and added with $15-40 \mu \mathrm{L}$ of DEPC water to dissolve the pellet.

\section{Purity detection}

A $1 \mu \mathrm{L}$ RNA sample 50 times diluted was taken and the optical density (OD) value was measured on a nucleic acid protein analyzer (BioPhotometer D30, Eppendorf). A ratio of OD260/OD280 is greater than 1.8 , indicating that the prepared RNA is pure and free of protein pollution.

\section{Total RNA integrity detection}

A $1 \mu \mathrm{L}$ of RNA sample was taken, and electrophoresis was performed on $1 \%$ agarose gel at $80 \mathrm{~V} \times 20 \mathrm{~min}$. The $5 \mathrm{~s}$ ribosomal RNA (rRNA), 18s rRNA, and 28s rRNA bands of total RNA were observed using a gel imaging system. All three bands being complete indicated that total RNA extraction was relatively complete. Reverse transcription was performed by taking the RNA with better integrity and higher purity extracted and separated according to the aforementioned steps.

\section{In the RNase-free polymerase chain reaction (PCR) tube, the following solutions were configured}

Total RNA, $1 \mu \mathrm{g}$; total volume $12 \mu \mathrm{L}$, filled with $\mathrm{H}_{2} \mathrm{O}$. The above solution was pipetted evenly and incubated at $85{ }^{\circ} \mathrm{C}$ for $5 \mathrm{~min}$ to denature the RNA. It was then immediately frozen on ice to prevent RNA renaturation. 
The following reagents (Promega) were added to the PCR tube

Oligo (dT), $0.5 \mu \mathrm{L}$; Random primer, $0.5 \mu \mathrm{L} ; 10 \mathrm{mM}$ deoxynucleoside triphosphate (dNTP), $2 \mu \mathrm{L}$; RNase inhibitor, $0.5 \mu \mathrm{L} ; 5 \times$ buffer, $4 \mu \mathrm{L} ; \mathrm{M}-\mathrm{MLV}, 0.5 \mu \mathrm{L}$. The total volume was $8 \mu \mathrm{L}$. The above $20 \mu \mathrm{L}$ reaction solution was incubated at $30{ }^{\circ} \mathrm{C}$ for $10 \mathrm{~min} ; 42^{\circ} \mathrm{C}$ for $60 \mathrm{~min}$; and $85^{\circ} \mathrm{C}$ for $10 \mathrm{~min}$.

\section{Quantitative PCR (qPCR)}

Quantitative PCR (qPCR) was used to detect the expression of FOXN1 and ER $\beta$, with $18 \mathrm{~s}$ used as an internal reference. The primers were purchased from Guangzhou GENEWIZ Company. The primer sequences were as follows: FOXN1-F, 5'-GCTCCTCACACTATCAGTACC-3'; FOXN1-R, 5'-AAGATGAGGATGCTGTAGGA-3'; ER $\beta$-F, 5'-GGCATGCGAGTAACAAGGGC-3'; ER $\beta-$ R, 5'-GGGAGCCCTCTTTGCTTTT-3'; GAPDH-F, 5'-GAGAAGTATGACAACAGCCTC-3'; GAPDH-R, 5'-ATGGACTGTGGTCATGAGTC-3'.

The reaction system was prepared as follows: complementary DNA (cDNA) $(1: 20), 5 \mu \mathrm{L}$; upstream primer, $0.5 \mu \mathrm{L}$; downstream primer, $0.5 \mu \mathrm{L} ; 2 \times$ SYBR Green qPCR SuperMix, $10 \mu \mathrm{L}$; dH2O, $4 \mu \mathrm{L}$; total volume, $20 \mu \mathrm{L}$. The reaction conditions were as follows: $5 \mathrm{~min}$ at $95^{\circ} \mathrm{C}, 40$ cycles of $15 \mathrm{~s}$ at $95^{\circ} \mathrm{C}$, and $32 \mathrm{~s}$ at $60^{\circ} \mathrm{C}$. Melting curve analysis: temperature was $60-95^{\circ} \mathrm{C}$. Each sample was repeated three times. SYBR Green qPCR SuperMix was purchased from Invitrogen. ABI PRISM ${ }^{\circledR} 7500$ Sequence Detection System was used as the qPCR instrument.

\section{Analysis of dual luciferase reporter gene activity}

The FOXN1 promoter vector was synthesized and purchased from Guangzhou RiboBio Co., Ltd. HUVEC were cultured in 96-well plates for 24 hours, transfected with control siRNA or ER $\beta$ siRNA, and cultured for 48 hours. The dual luciferase reporter gene kit (Promega, USA) was used to detect the effect of ER $\beta$ on FOXN1 promoter activity, and Renilla luciferase activity was used as a normalized internal reference.

\section{Analysis of reactive oxygen species (ROS) and superoxide dismutase (SOD) content}

In HUVEC, the effects of ET-1, ER $\beta$, and FOXN1 on ROS and SOD levels were analyzed in the samples of the blank control (cell), siRNA control (NC), ER $\beta$ siRNA, FOXN1 siRNA, ET-1, ET-1 + NC, ET-1 + ER $\beta$ siRNA, and ET-1 + FOXN1 siRNA groups using a ROS and SOD detection kit.

\section{Flow cytometry to detect cell cycle}

Cells in different groups were examined by flow cytometry. $1 \times 10^{6}$ cells in each group were collected 48 hours after cell transfection.

\section{Cell fixation}

Cells were collected by centrifugation, and the supernatant was discarded. Cells were placed in precooled $70 \%$ ethanol at $-20{ }^{\circ} \mathrm{C}$ for fixation overnight. The cells were washed twice with precooled PBS, and placed in precooled $70 \%$ ethanol for fixation overnight or long-term fixation at $-20^{\circ} \mathrm{C}$.

\section{Cell staining}

Cells were collected by centrifugation, and washed once with 1 $\mathrm{mL}$ PBS. Next, $500 \mu \mathrm{L}$ PBS [containing $50 \mu \mathrm{g} / \mathrm{mL}$ propidium bromide (PI)] and $100 \mu \mathrm{g} / \mathrm{mL}$ RNase A, $0.2 \%$ Triton X-100 was added and incubated at $4{ }^{\circ} \mathrm{C}$ in the dark for $30 \mathrm{~min}$.

\section{Flow cytometry assay}

The cell cycle was detected by flow cytometry in accordance with standard procedures. Generally, 2-3 million cells were counted, and the results were analyzed using the cell cycle fitting software, ModFit. Flow cytometer (BD calibur) was used to detect the cell cycle.

\section{Western blot assay}

After digesting HUVEC cells in each group, total protein was extracted and the total protein concentration in each group of cells was determined using the bicinchoninic acid (BCA) method. Each group was loaded with $30 \mu \mathrm{g}$ of total protein and subjected to sodium dodecyl sulfatepolyacrylamide (SDS-PAGE) gel electrophoresis. After $50 \mathrm{~min}$, it was transferred to a polyvinylidene difluoride (PVDF) membrane and a constant voltage of $100 \mathrm{~V}$ for 60 $120 \mathrm{~min}$. The cells were then incubated at $4{ }^{\circ} \mathrm{C}$ overnight or at $37{ }^{\circ} \mathrm{C}$ for 2 hours in an appropriate concentration dilution of primary antibody and incubated in a dilution of corresponding secondary antibody at $37{ }^{\circ} \mathrm{C}$ for 1 hour. Following the incubation, the cells were washed with Trisbuffered saline, $0.1 \%$ Tween 20 (TSBT) three times, and developed using the enhanced chemiluminescence (ECL) method. The antibodies and reagents used in the Western 
A

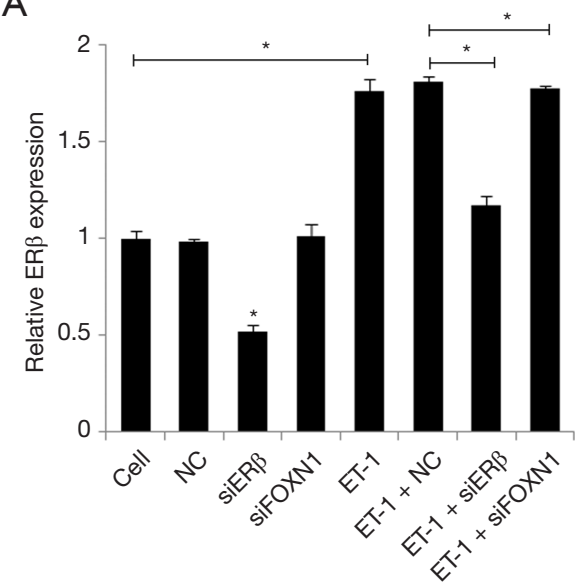

B

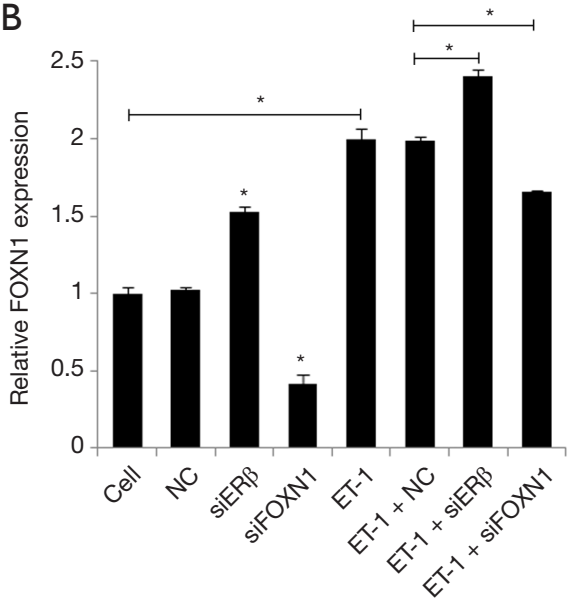

Figure 1 Expression levels of FOXN1 and ER $\beta$ in the eight groups. (A) Expression levels of ER $\beta$ in the eight groups; (B) expression levels of FOXN1 in the eight groups. *, $\mathrm{P}<0.05$. FOXN1, Forkhead box protein N1.

blot analysis were as follows: horseradish peroxidase (HRP)-labeled glyceraldehyde 3-phosphate dehydrogenase (GAPDH) internal reference (Shanghai Kangcheng Bio, KC-5G5); anti-FOXN1 antibody (bioss, bs-6970R); antiestrogen related receptor beta antibody (abcam, ab19331); recombinant anti-cyclin A2 antibody (abcam, ab181591); recombinant anti-cyclin B1 antibody (abcam, ab32053); cyclin D1/follistatin like 3 (FSTL3) (Bioss, bs-0623R); cyclin E1 (D7T3U) rabbit monoclonal antibodies (mAb) (CST, 20808); rabbit anti-mouse immunoglobulin G (IgG) (southern biotech, 6170-05); goat anti-rabbit IgG (southern biotech, 4050-05); peroxidase-labeled rabbit anti-goat IgG (Wuhan BOSTER Biological Technology Co., Ltd., BA1060); peroxide enzyme-labeled rabbit antirat IgG (Wuhan BOSTER Biological Technology Co., Ltd., BA1058); medical X-ray film (Kodak); luminescent solution (IMMOBILON WESTERN CHEMILUM HRP SUBSTRATE, MILLIPORE, WBKLS0500); PVDF membrane (Immobilon-P Transfer Membrane, MILLIPORE, IPVH00010).

\section{Statistical processing}

Data were statistically analyzed using SPSS 17.0 software. One-way analysis of variance (ANOVA) was used for comparison between multiple groups under homogeneity of variance, and the $t$-test was used for pairwise comparison between multiple groups. $\mathrm{P}<0.05$ was considered statistically significant.

\section{Results}

\section{Effect of ET-1 on the expression of ERB and FOXN1}

A real-time qPCR (RT-qPCR) assay was used to detect the effect of ET- 1 on the expression of ER $\beta$ and FOXN1, and the relationship between ER $\beta$ and FOXN1. The results showed that the ER $\beta$ and FOXN1 expression levels of in the cells of the ET-1 group were significantly increased compared with the cell group $(\mathrm{P}<0.05)$. Also, compared with the NC group, the ER $\beta$ mRNA expression level in the ER $\beta$ siRNA group was markedly reduced $(\mathrm{P}<0.05)$, the FOXN1 mRNA expression level was considerably increased $(\mathrm{P}<0.05)$, and the FOXN1 mRNA expression level in the FOXN1 siRNA group was notably decreased $(\mathrm{P}<0.05)$. The ER $\beta$ mRNA expression level was not statistically significant $(\mathrm{P}>0.05)$. Also, compared with the ET-1 + NC group, the ER $\beta$ mRNA expression level in the ET-1 + ER $\beta$ siRNA group was significantly reduced $(\mathrm{P}<0.05)$, and the FOXN1 mRNA expression level was increased $(\mathrm{P}<0.05)$. The FOXN1 mRNA expression level in the ET-1 + FOXN1 siRNA group was reduced $(\mathrm{P}<0.05)$. Furthermore, the ER $\beta$ mRNA expression level was not statistically significant $(\mathrm{P}>0.05)$. There was also no statistical significance between the ET-1 group and the ET-1 + NC group $(\mathrm{P}>0.05)$. These results indicate that ET-1 can promote the expression of FOXN1 and $\mathrm{ER} \beta$, and that ER $\beta$ can inhibit the expression of FOXN1. Moreover, FOXN1 has no significant effect on the expression of $\operatorname{ER} \beta$ (Figure 1A,B). 


\section{Effect of ERß on FOXN1 promoter luciferase reporter gene activity}

Next, we used the dual luciferase reporter gene assay to explore the effect of ER $\beta$ on FOXN1 promoter luciferase reporter gene activity. The results showed that FOXN1 promoter luciferase reporter gene activity was significantly enhanced in the ER $\beta$ siRNA group compared to the siRNA control group, indicating that ER $\beta$ may inhibit FOXN1 at

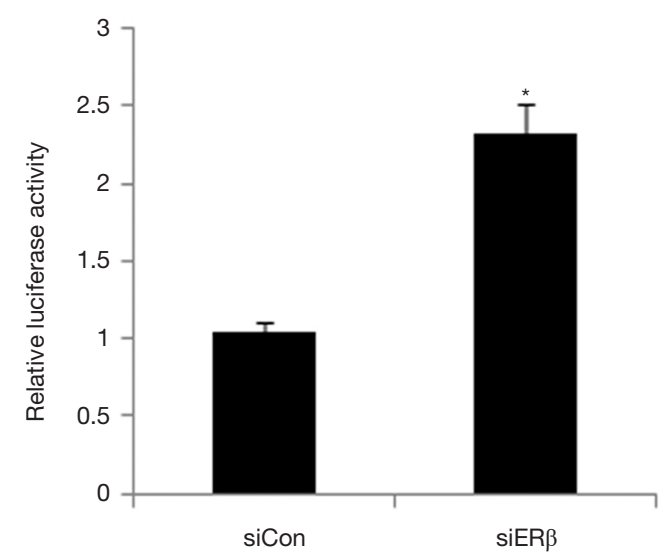

Figure 2 Dual-luciferase reporter analysis of the effect of $\operatorname{ER} \beta$ on the luciferase activity of FOXN1 promoter. * $\mathrm{P}<0.05$.

A

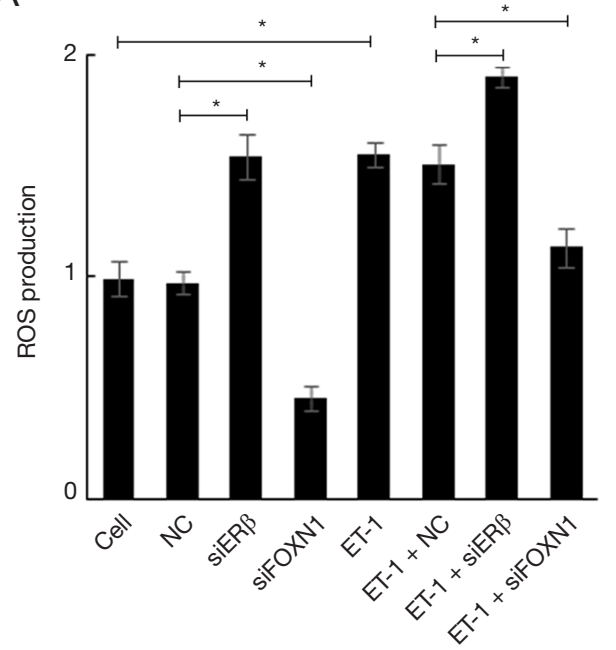

the transcriptional level (Figure 2).

\section{Effect of ET-1, ERß and FOXN1 on ROS and SOD levels}

We examined the effects of ET-1, ER $\beta$, and FOXN1 on the levels of ROS (Figure 3A) and SOD (Figure 3B). We found that the level of ROS in the ET-1 group increased markedly $(\mathrm{P}<0.05)$, and the level of SOD decreased substantially $(\mathrm{P}<0.05)$ compared with the cell group. Also, compared with the NC group, the level of ROS in the ER $\beta$ siRNA group was notably increased $(\mathrm{P}<0.05)$, the level of SOD was significantly reduced $(\mathrm{P}<0.05)$, the level of ROS in the FOXN1 siRNA group was decreased $(\mathrm{P}<0.05)$, and the level of SOD was increased $(\mathrm{P}<0.05)$. Moreover, compared with the ET-1 + NC group, the ROS level in the ET-1 + ER $\beta$ siRNA group was increased $(\mathrm{P}<0.05)$, and the SOD level was decreased $(\mathrm{P}<0.05)$. The level of ROS in the ET-1 + FOXN1 siRNA group decreased significantly $(\mathrm{P}<0.05)$, while the level of SOD increased considerably $(\mathrm{P}<0.05)$. There were no statistical significances between the cell and $\mathrm{NC}$ groups $(\mathrm{P}>0.05)$, or between the ET-1 group and the ET-1 + NC group $(\mathrm{P}>0.05)$. These results indicate that ET-1 and FOXN1 can increase ROS levels and reduce SOD levels, while ER $\beta$ can inhibit ROS levels and enhance SOD levels.

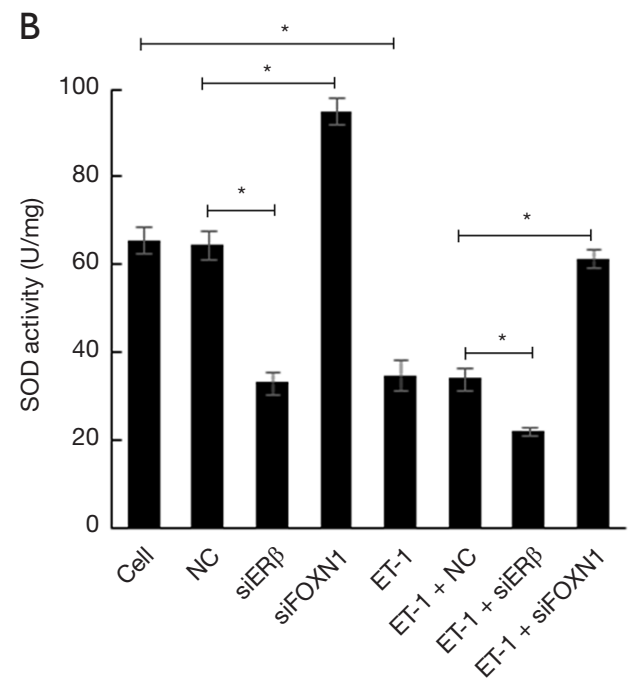

Figure 3 The effect of ET-1, ER $\beta$, and FOXN1 on the levels of ROS and SOD. (A) The effect of ET-1, ER $\beta$, and FOXN1 on the levels of ROS; (B) the effect of ET-1, ER $\beta$, and FOXN1 on the levels of SOD. *, P<0.05. FOXN1, Forkhead box protein N1. 
A

Cell
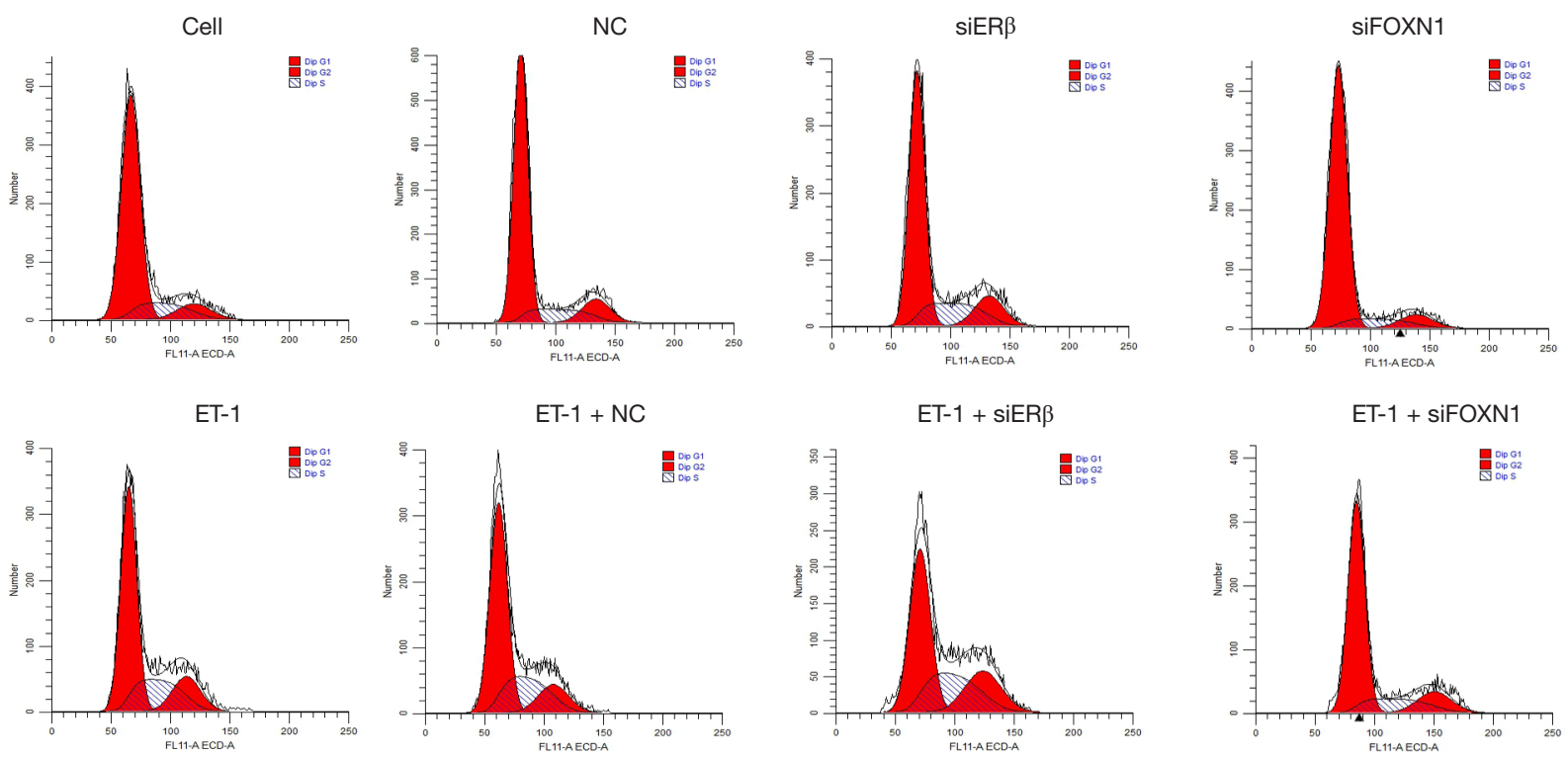

B

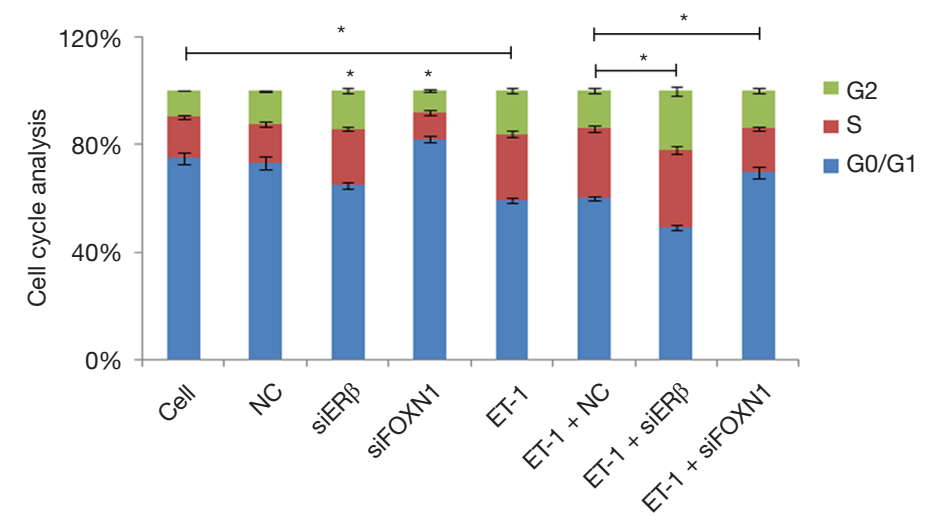

Figure 4 Flow cytometry analysis of cell cycle in the eight groups. (A,B) Flow cytometry analysis of cell cycle in the eight groups. *, $\mathrm{P}<0.05$. FOXN1, Forkhead box protein N1.

\section{Effect of ET-1, ERB, and FOXN1 on cell cycle}

We also employed flow cytometry to analyze the effect of ET-1, ER $\beta$, and FOXN1 on the cell cycle. Compared with the cell group, the ratio of cells in the G0/G1 phase decreased in the ET-1 group, while the ratio of cells in the $\mathrm{S}$ and G2 phase increased $(\mathrm{P}>0.05)$. Also, the ratio of cells in the G0/G1 phase decreased, and the ratio of cells in the $\mathrm{S}$ and $\mathrm{G} 2$ phase increased in the ER $\beta$ siRNA group compared with the NC group $(\mathrm{P}>0.05)$. In the FOXN1 siRNA group, the ratio of cells in the G0/G1 phase increased, while the ratio in the $\mathrm{S}$ and $\mathrm{G} 2$ phase decreased $(\mathrm{P}>0.05)$. Furthermore, the ratio of cells in the G0/G1 phase decreased, and the cell ratio of $S$ and G2 phase increased in the ET-1 + ER $\beta$ siRNA group compared with the ET-1 $+\mathrm{NC}$ group $(\mathrm{P}>0.05)$. Meanwhile, the cell ratio in the G0/ G1 phase increased, and the cell ratio in the $\mathrm{S}$ and G2 phase decreased in the ET-1 + FOXN1 siRNA group $(\mathrm{P}>0.05)$. There were no statistically significant differences between the cell and NC groups $(\mathrm{P}>0.05)$, or between the ET- 1 and ET-1 + NC groups $(\mathrm{P}>0.05)$ (Figure 4A,B).

\section{Effects of ET-1, ERß and FOXN1 on cell cycle-related proteins}

Finally, we used Western blot assay to observe the effects of ET-1, ER $\beta$, and FOXN1 on cell cycle protein expression. 

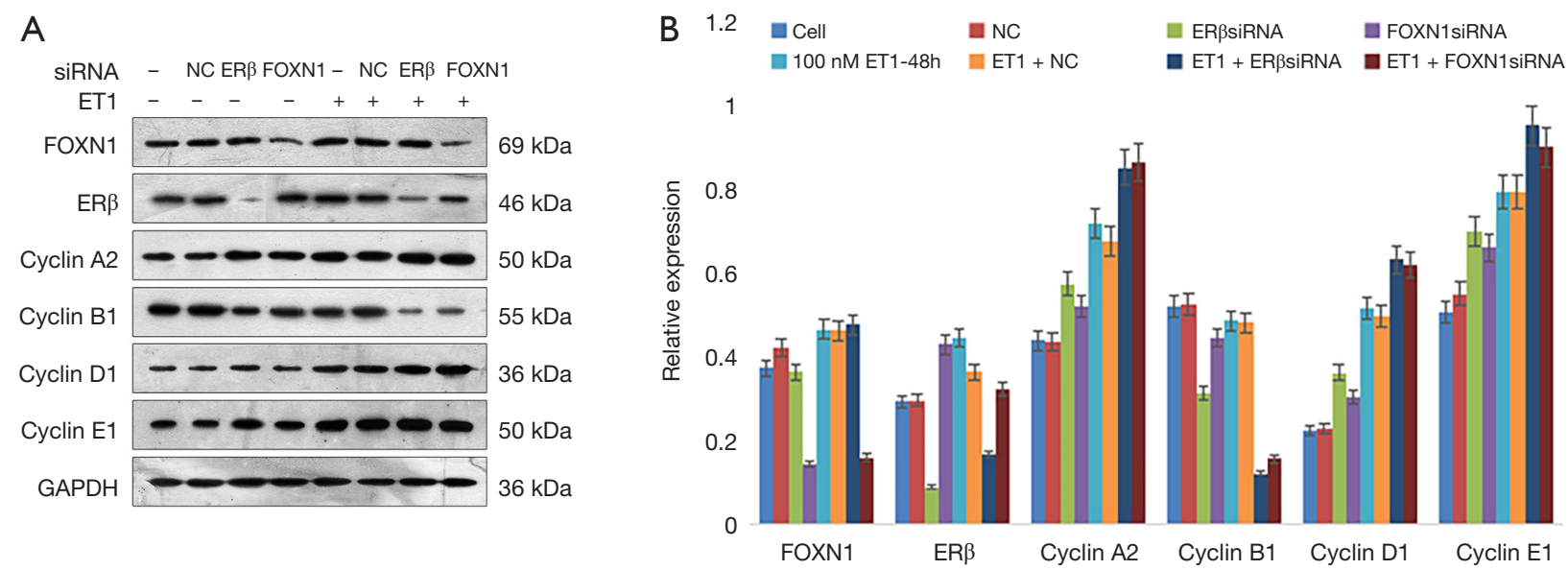

Figure 5 Western blot analysis of the protein expression related to cell cycle in the eight groups. (A,B) Western blot analysis of the protein expression related to cell cycle in the eight groups. FOXN1, Forkhead box protein N1.

As shown in Figure $5 A, B$, the protein expressions of ER $\beta$, FOXN1, CCNA2, CCNB1, CCND1, and CCNE1 in the ET-1 group were significantly increased compared with the cell group $(\mathrm{P}>0.05)$. Also, compared with the $\mathrm{NC}$ group, the protein expressions of ER $\beta$ and CCNB1 in the cells of the ER $\beta$ siRNA group were significantly reduced, while the protein expressions of CCNA2, CCND1, and CCNE1 were significantly increased $(\mathrm{P}<0.05)$. There was no significant change in the protein level of FOXN1 $(\mathrm{P}>0.05)$.

The protein expressions of FOXN1 and CCNB1 in the cells of the FOXN1-siRNA group were reduced, while the protein expressions of ER $\beta$, CCNA2, CCND1, and CCNE1 were increased, and the difference was statistically significant $(\mathrm{P}<0.05)$. Furthermore, the protein expressions of ER $\beta$ and CCNB1 in the ET- 1 + ER $\beta$ siRNA group were reduced, and the protein expressions of CCNA2, CCND1, and CCNE1 were significantly increased compared with the ET-1 + NC group, and the difference was statistically significant $(\mathrm{P}<0.05)$. There was no significant change in the protein level of the FOXN1 $(\mathrm{P}>0.05)$.

The protein expressions of FOXN1 and CCNB1 in the ET-1 + FOXN1-siRNA group were significantly reduced, and the protein expressions of CCNA2, CCND1 and CCNE1 were significantly increased, and the difference was statistically significant $(\mathrm{P}<0.05)$. Meanwhile, there was no significant change in protein level of $\operatorname{ER} \beta(\mathrm{P}>0.05)$. There was also no significant difference between the ET-1 and ET $-1+\mathrm{NC}$ groups $(\mathrm{P}>0.05)$. These results indicate that ET-1, ER $\beta$, and FOXN1 may be involved in cell cycle regulation.

\section{Discussion}

Atherosclerosis is a unique form of arteriosclerosis, and essentially refers to the thickening of arterial walls, especially due to the invasion and accumulation of white blood cells and the proliferation of intimal smooth muscle cells (24). Endothelial cells maintain the steady state of the vascular system, and abnormal proliferation and apoptosis of VECs promote the development of atherosclerosis (25). The early stage of atherosclerosis is related to the elevated levels of oxidized low density lipoprotein (ox-LDL), oxidative stress, adhesion molecules and inflammatory cytokines in the vascular endothelium $(26,27)$. Therefore, treatment strategies for vascular endothelial cell oxidative stress (28) and apoptosis (12) may inhibit the initiation and progression of AS. Previous studies have shown that ET-1 can regulate endothelial cell function by mediating superoxide production (29). Vitamin D has been shown to reduce vascular remodeling and ischemia by up-regulating the expression of ET-1, ethidium bromide (ETBR), and endothelial nitric oxide synthase 3 (eNOS), thereby improving renal fibrosis (30). Interestingly, we found that ET- 1 can promote the expression of FOXN1 and ER $\beta$ in HUVEC, and that ER $\beta$ can inhibit FOXN1 expression by regulating promoter activity. This discovery provides a novel target protein and mechanism for the regulation of ET-1.

Recent studies have shown that long non-coding RNA $\mathrm{X}$-inactive specific transcript (XIST) regulates oxidative stress damage in HUVEC by regulating micro RNA-2045p/Toll-like receptor 4 (miR-204-5p/TLR4) (31). Also, 
methyltransferase G9a can mediate oxidative stress in HUVEC (32). Oxidative stress meditated via the Septin4/ Poly (ADP-ribose) polymerase 1 (PARP1) signaling pathway promotes HUVEC damage (33). Moreover, the interaction of non-coding RNA and the p53 signaling pathway is also involved in the regulation of oxidative stress in HUVEC (34). Additionally, rapamycin-mediated autophagy can regulate the oxidative stress response in HUVEC (35). Epigallocatechin-3-gallate (EGCG) can improve Angiotensin II-mediated HUVEC oxidative damage and apoptosis by activating the nuclear factor erythroid 2-related factor 2 (Nrf2)/Caspase-3 signaling pathway (36). In this study, we found that ET-1, ER $\beta$, and FOXN1 can regulate ROS and SOD levels, thereby providing an original mechanism for the abnormal regulation of oxidative stress of endothelial cells.

Previous studies have revealed that ET-1 promotes the proliferation of VSMCs by regulating extracellular signalregulated kinase and cyclin D1 (37). Also, 17- $\beta$-estradiol inhibits senescence of human umbilical endothelial cells by regulating p53 autophagy (38). Meanwhile, ET-1 stimulates the expression of cyclin D1 and S-phase kinaserelated protein 2 by activating the signal transducer and activator of transcription 3 (STAT3) transcription factor in cultured rat astrocytes (39). In addition, ER $\beta$ inhibits the proliferation of anterior pituitary cells by controlling the expression of proteins associated with cell cycle progression (40). ER $\beta$ also inhibits cyclin-dependent kinase 1 (CDK1) activity by regulating cyclin $\mathrm{B} 1$, growth arrest and DNA damage inducible alpha (GADD45A), and BTG AntiProliferation Factor 2 (BTG2), which leads to G2 cell cycle arrest (41). Additionally, ER $\beta$ alters cyclin expression in a ligand-dependent manner to regulate tumorigenesis (42). Previous reports have shown that FOXN1 can participate in the regulation of the cell cycle $(43,44)$. In this study, we determined that ET-1, ER $\beta$, and FOXN1 can regulate the expression of cell cycle-related proteins CCNB1, CCNA2, CCND1, and CCNE1 in HUVEC, and affect cell cycle progression. This discovery reveals novel functions of ET1, ER $\beta$, and FOXN1 in the regulation of HUVEC cycle.

\section{Conclusions}

In summary, we conclude that ET-1 can promote the expression of ER $\beta$ and FOXN1, and that ER $\beta$ can inhibit the expression of FOXN1 by regulating promoter activity. The ET-1/ER $\beta / F O X N 1$ signaling pathway is involved in the regulation of oxidative stress and cycle progression of umbilical vein endothelial cells. This study provides an original mechanism for the regulation of umbilical vein endothelial cells. The ET-1/ER $\beta / F O X N 1$ signaling pathway may provide novel targets and strategies for the treatment of atherosclerosis.

\section{Acknowledgments}

Thanks go to Guangzhou Yujia Biotechnology Co., Ltd. for their help in the field.

Funding: None.

\section{Footnote}

Reporting Checklist: The authors have completed the MDAR reporting checklist. Available at http://dx.doi.org/10.21037/ atm-20-6560

Data Sharing Statement: Available at http://dx.doi. org/10.21037/atm-20-6560

Conflicts of Interest: All authors have completed the ICMJE uniform disclosure form (available at http://dx.doi. org/10.21037/atm-20-6560). The authors have no conflicts of interest to declare.

Ethical Statement: The authors are accountable for all aspects of the work in ensuring that questions related to the accuracy or integrity of any part of the work are appropriately investigated and resolved.

Open Access Statement: This is an Open Access article distributed in accordance with the Creative Commons Attribution-NonCommercial-NoDerivs 4.0 International License (CC BY-NC-ND 4.0), which permits the noncommercial replication and distribution of the article with the strict proviso that no changes or edits are made and the original work is properly cited (including links to both the formal publication through the relevant DOI and the license). See: https://creativecommons.org/licenses/by-nc-nd/4.0/.

\section{References}

1. Zhu Y, Xian X, Wang Z, et al. Research Progress on the Relationship between Atherosclerosis and Inflammation. Biomolecules 2018;8:80.

2. Huynh K. Atherosclerosis: Trehalose induces macrophage autophagy-lysosomal biogenesis. Nat Rev Cardiol 


\section{Page 10 of 11}

2017;14:444.

3. Sima P, Vannucci L, Vetvicka V. Atherosclerosis as autoimmune disease. Ann Transl Med. 2018;6:116.

4. Tarbell J, Mahmoud M, Corti A, et al. The role of oxygen transport in atherosclerosis and vascular disease. J R Soc Interface 2020;17:20190732.

5. Xu S. Therapeutic potential of blood flow mimetic compounds in preventing endothelial dysfunction and atherosclerosis. Pharmacol Res 2020;155:104737.

6. Peng Z, Shu B, Zhang Y, et al. Endothelial Response to Pathophysiological Stress. Arterioscler Thromb Vasc Biol 2019;39:e233-43.

7. Chen ZW, Tsai CH, Pan CT, et al. Endothelial Dysfunction in Primary Aldosteronism. Int J Mol Sci 2019;20:5214.

8. Lee DY, Chiu JJ. Atherosclerosis and flow: roles of epigenetic modulation in vascular endothelium. J Biomed Sci 2019;26:56.

9. Rodríguez-Rodríguez VE, Martínez-González B, Quiroga-Garza A, et al. Human Umbilical Vessels: Choosing the Optimal Decellularization Method. Asaio j 2018;64:575-80.

10. Kocherova I, Bryja A, Mozdziak P, et al. Human Umbilical Vein Endothelial Cells (HUVECs) Co-Culture with Osteogenic Cells: From Molecular Communication to Engineering Prevascularised Bone Grafts. J Clin Med 2019;8:1602.

11. Hastie R, Tong S, Hannan NJ, et al. Epidermal growth factor rescues endothelial dysfunction in primary human tissues in vitro. Reprod Sci 2017;24:1245-52.

12. Gong L, Lei Y, Liu Y, et al. Vaccarin prevents ox-LDLinduced HUVEC EndMT, inflammation and apoptosis by suppressing ROS/p38 MAPK signaling. Am J Transl Res 2019;11:2140-54.

13. Eroglu E, Kocyigit I, Lindholm B. The endothelin system as target for therapeutic interventions in cardiovascular and renal disease. Clin Chim Acta 2020;506:92-106.

14. Davenport AP, Kuc RE, Southan C, et al. New drugs and emerging therapeutic targets in the endothelin signaling pathway and prospects for personalized precision medicine. Physiol Res 2018;67:S37-54.

15. Hostenbach S, D'Haeseleer M, Kooijman R, et al. The pathophysiological role of astrocytic endothelin-1. Prog Neurobiol 2016;144:88-102.

16. Patel S, Homaei A, Raju AB, et al. Estrogen: The necessary evil for human health, and ways to tame it. Biomed Pharmacother 2018;102:403-11.

17. White RE. Estrogen and vascular function. Vascul

\section{Wang et al. ET-1 regulates HUVEC cycle by ERß/FOXN1 pathway}

Pharmacol 2002;38:73-80.

18. Iorga A, Cunningham CM, Moazeni S, et al. The protective role of estrogen and estrogen receptors in cardiovascular disease and the controversial use of estrogen therapy. Biol Sex Differ 2017;8:33.

19. Acconcia F, Fiocchetti M, Marino M. Xenoestrogen regulation of $\mathrm{ER} \alpha / \mathrm{ER} \beta$ balance in hormone-associated cancers. Mol Cell Endocrinol 2017;457:3-12.

20. Palamaro L, Romano R, Fusco A, et al. FOXN1 in organ development and human diseases. Int Rev Immunol 2014;33:83-93.

21. Grabowska AI, Wilanowski T. FOXN1 Transcription Factor in Epithelial Growth and Wound Healing. Mol Cell Biol 2017;37:e00110-7.

22. Ghezzo MN, Fernandes MT, Pacheco-Leyva I, et al. FoxN1-dependent thymic epithelial cells promote T-cell leukemia development. Carcinogenesis 2018;39:1463-76.

23. Uddin MM, Ohigashi I, Motosugi R, et al. Foxn $1-\beta 5 \mathrm{t}$ transcriptional axis controls CD8(+) T-cell production in the thymus. Nat Commun 2017;8:14419.

24. Hu C, Huang S, Wu F, et al. miR-98 inhibits cell proliferation and induces cell apoptosis by targeting MAPK6 in HUVECs. Exp Ther Med 2018;15:2755-60.

25. Olejarz W, Bryk D, Zapolska-Downar D, et al. Mycophenolic acid attenuates the tumour necrosis factor$\alpha$-mediated proinflammatory response in endothelial cells by blocking the MAPK/NF- $\mathrm{B}$ and ROS pathways. Eur J Clin Invest 2014;44:54-64.

26. Yao Y, Wang Y, Zhang Y, et al. Klotho ameliorates oxidized low density lipoprotein (ox-LDL)-induced oxidative stress via regulating LOX-1 and PI3K/Akt/eNOS pathways. Lipids Health Dis 2017;16:77.

27. Brown DI, Griendling KK. Regulation of signal transduction by reactive oxygen species in the cardiovascular system. Circ Res 2015;116:531-49.

28. Mao H, Tao T, Wang X, et al. Zedoarondiol Attenuates Endothelial Cells Injury Induced by Oxidized LowDensity Lipoprotein via Nrf2 Activation. Cell Physiol Biochem 2018;48:1468-79.

29. Cerrato R, Crabtree M, Antoniades C, et al. Effects of Endothelin-1 on intracellular tetrahydrobiopterin levels in vascular tissue. Scand Cardiovasc J 2018;52:163-9.

30. Arfian N, Kusuma MH, Anggorowati N, et al. Vitamin D upregulates endothelin-1, ETBR, eNOS mRNA expression and attenuates vascular remodelling and ischemia in kidney fibrosis model in mice. Physiol Res 2018;67:S137-47.

31. Lu G, Tian P, Zhu Y, et al. LncRNA XIST knockdown 
ameliorates oxidative low-density lipoprotein-induced endothelial cells injury by targeting miR-204-5p/TLR4. J Biosci 2020;45:52.

32. Wan S, Yang W, Pan Y, et al. G9a Suppression Alleviates Corneal Neovascularization through Blocking Nox4Mediated Oxidative Stress. Oxid Med Cell Longev 2020;2020:6983268.

33. Zhang N, Zhang Y, Zhao S, et al. Septin4 as a novel binding partner of PARP1 contributes to oxidative stress induced human umbilical vein endothelial cells injure. Biochem Biophys Res Commun 2018;496:621-7.

34. Fuschi P, Carrara M, Voellenkle C, et al. Central role of the $\mathrm{p} 53$ pathway in the noncoding-RNA response to oxidative stress. Aging (Albany NY) 2017;9:2559-86.

35. Rezabakhsh A, Ahmadi M, Khaksar M, et al. Rapamycin inhibits oxidative/nitrosative stress and enhances angiogenesis in high glucose-treated human umbilical vein endothelial cells: Role of autophagy. Biomed Pharmacother 2017;93:885-94.

36. Zhou X, Liang L, Zhao Y, et al. Epigallocatechin-3-Gallate Ameliorates Angiotensin II-Induced Oxidative Stress and Apoptosis in Human Umbilical Vein Endothelial Cells through the Activation of Nrf2/Caspase-3 Signaling. J Vasc Res 2017;54:299-308.

37. Zhang YM, Wang KQ, Zhou GM, et al. Endothelin-1 promoted proliferation of vascular smooth muscle cell through pathway of extracellular signal-regulated kinase and cyclin D1. Acta Pharmacol Sin 2003;24:563-8.

38. Song S, Wu S, Wang Y, et al. 17ß-estradiol inhibits human

Cite this article as: Wang Y, Ruan Y, Wu S. ET-1 regulates the human umbilical vein endothelial cell cycle by adjusting the ER $\beta / F O X N 1$ signaling pathway. Ann Transl Med 2020;8(22):1499. doi: 10.21037/atm-20-6560 umbilical vascular endothelial cell senescence by regulating autophagy via p53. Exp Gerontol 2018;114:57-66.

39. Koyama Y, Sumie S, Nakano Y, et al. Endothelin-1 stimulates expression of cyclin D1 and S-phase kinaseassociated protein 2 by activating the transcription factor STAT3 in cultured rat astrocytes. J Biol Chem 2019;294:3920-33.

40. Pérez PA, Petiti JP, Wagner IA, et al. Inhibitory role of $\mathrm{ER} \beta$ on anterior pituitary cell proliferation by controlling the expression of proteins related to cell cycle progression. Mol Cell Endocrinol 2015;415:100-13.

41. Paruthiyil S, Cvoro A, Tagliaferri M, et al. Estrogen receptor $\beta$ causes a $\mathrm{G} 2$ cell cycle arrest by inhibiting $\mathrm{CDK} 1$ activity through the regulation of cyclin B1, GADD45A, and BTG2. Breast Cancer Res Treat 2011;129:777-84.

42. Liu YS, Tsai YL, Yeh YL, et al. Cell Cycle Regulation in the Estrogen Receptor Beta (ESR2)-Overexpressing Hep3B Hepatocellular Carcinoma Cell Line. Chin J Physiol 2015;58:134-40.

43. Ma D, Wang L, Wang S, et al. Foxn1 maintains thymic epithelial cells to support T-cell development via $\mathrm{mcm} 2$ in zebrafish. Proc Natl Acad Sci U S A 2012;109:21040-5.

44. Chen HY, Lin PH, Shih YH, et al. Natural antioxidant resveratrol suppresses uterine fibroid cell growth and extracellular matrix formation in vitro and in vivo. Antioxidants (Basel) 2019;8:99.

(English Language Editor: A. Kassem) 